\title{
Development of Suspended Particulate Matter Empirical Equation for Tropics Estuary from Landsat ETM+ Data
}

\author{
Z. RAZAK ${ }^{1}$, A. ZUHAIRI ${ }^{2 *}$, S. SHAHBUDIN ${ }^{3}$ AND Y. ROSNAN ${ }^{4}$
}

Suspended Particulate Matter (SPM) essentially related to the total scattering of particles in the water column. It plays the role as a transport medium for pollutants, total load of organic and inorganic substance in the water phase. In this study, we have developed empirical relationship based on a strong relationship between Landsat near infrared (NIR) band and archived SPM data. The following were the power equations:

$$
\begin{aligned}
& \text { SPM NE }(\mathrm{mg} / \mathrm{l})=11.68 x^{0.666} \\
& \operatorname{SPM~SW~}(\mathrm{mg} / \mathrm{l})=18.61 x^{0.493}
\end{aligned}
$$

where, $x$ (TM4) is radiance of ETM+ NIR band 4 was developed under tropical atmospheric conditions. Using the above equation, the SPM concentration for Northeast and Southwest monsoon in the Pahang River estuary as a case study was determined. The mean SPM concentration and mean reflectance value during Northeast monsoon were $131.69 \mathrm{mg} / 1$ and $0.135 \mathrm{mg} / \mathrm{l}$. The mean SPM concentration value and reflectance were $95.94 \mathrm{mg} / \mathrm{l}$ and $0.078 \mathrm{mg} / \mathrm{l}$ during the Southwest monsoon. Generally, from remote sensing archive data and above equations, the SPM concentrations of Pahang River were successfully determined from 1999 to 2012.

Key words: Suspended particulate matter; Pahang River estuary; Landsat ETM+; historical data; water quality

Suspended sediment particulate plays an important role in estuary ecology, as it is one of the major features affecting sedimentation and accretion. Conventional field methods for monitoring SPM are time consuming and expensive. One of the alternative methods is using remote sensing techniques to retrieve SPM concentrations from satellite image. Regression analysis is a significant representative of SPM concentrations and spectral reflectance relationship, which exclusively allow remotely sensed data to be used for monitoring sediments. Such efforts for empirical regression equations development were conducted by Milan and Pavla (2008), Kloiber et al. (2002), Wang et al. (2004), and Giardino et al. (2001).

Suspended particulate matter data derived from satellite sensors can be obtained based on reflectance from backscattering effect in the

\footnotetext{
${ }^{1}$ Faculty of Maritime and Marine Science, University Malaysia Terengganu, 21300, Kuala Terengganu, Terengganu, Malaysia.

${ }^{2}$ Marine Science Department, Kulliyyah of Science, International Islamic University Malaysia, Jalan Istana, Bandar Indera Mahkota, 25200, Kuantan, Pahang, Malaysia.

${ }^{3}$ Institute of Oceanography and Maritime Studies (INOCEM), Kulliyyah of Science, International Islamic University Malaysia, Jalan Istana, Bandar Indera Mahkota, 25200, Kuantan, Pahang, Malaysia.

${ }^{4}$ Faculty of Maritime and Marine Science, University Malaysia Terengganu, 21300, Kuala Terengganu, Terengganu, Malaysia.

* Corresponding author (e-mail: zuhairiahmad@iium.edu.my)
} 
visible and near infrared of spectrum regions. Mostly, high reflectance value will reflect high sediment suspension (Collen \& Tamlin, 2013). Nonetheless, the exact relationship of suspended SPM and reflectance also depends on the sediment characteristics, climate, atmospheric conditions and anthropogenic activities. These factors were highly variable in natural environment at different area under several circumstances. Therefore, most studies developed unique relationships in a particular area by relating in-situ SPM data and reflectance data from satellite imagery.

Several studies have been widely utilized Landsat 7 ETM+ (Enhanced Thematic Mapper Plus) for this purpose. It is often practical for Landsat 7 ETM+ data to be used for SPM monitoring despite its low spectral and radiometric resolution (Min et al. 2012; Kabbara et al. 2008; Islam et al. 2001). Surface SPM envisioned as natural tracer by Landsat 7 ETM+ bands two through four, which are sensitive reflective bands (Milan \& Pavla, 2008). Having the status of better than $5 \%$ data calibration, Landsat 7 ETM+ served as an on-orbit standard for cross-calibration of other Earth remote sensing missions. The image also acquired systematically to periodically refresh a global archive of sun-lit and substantially cloud-free images, thus optimizing the data acquisition strategy. There was a probability of recent data existing, hence it could be quickly retrieved to compare with newly acquired data. These features have proved the Landsat 7 data was important for a wide and diverse remote sensing applications including suspended sediment monitoring.

Thus, this application could be adapted to certain areas where the sedimentation problems occurred; either potentially or continuously with unpredicted monsoon factors such in Pahang River Estuary, Pahang. For the past ten years, sedimentation and erosion problems have occurred in Pahang River estuary, emerging sand banks and tidal shoals. It becomes a major defect especially to the local villagers as most of them are fisherman. Primary sources of the sediments were highly likely from the catchment areas upstream. Concerns have arisen on the river capacity as upstream areas are often faced with flooding during heavy rains. Numerous sand dredging sites also can be found in the Pahang River estuary. To date, more than ten different sites have been identified including sand dredging operations using vessels. During operational time, high suspended sediment concentrations were observed around the area which resulted for the poor water quality.

This study described the remote sensing analysis and calibration using archived satellite data and historical in-situ data to obtain suitable suspended particulate matter (SPM) equations based on previous studies, using the Pahang River estuary as a case study.

\section{Study Area}

The Pahang River estuary is in the east coast of Pahang, facing the South China Sea (Figure 1). The estuary received tidal flow from Kuala Pahang inlet and Tanjung Agas inlet, while freshwater from upstream. The Pahang River stretched for almost $440 \mathrm{~km}$ long and drained an area of $29071.32 \mathrm{~km}^{2}$ (Figure 2). The Pahang River is divided into the Tembeling and Jelai River, and meets at a confluence at Kuala Tembeling. The river meanders through Jerantut, Temerloh, Maran, Bera and Pekan. Annual rainfall in the catchment area ranged from $1609 \mathrm{~mm}$ to $2132.36 \mathrm{~mm}$ (Pan et al. 2011). The estuary also faced bimodal pattern of twomonsoon period.

In Malaysia, Northeast monsoon starts around October to March, and Peninsular Malaysia is expected to be wetter than normal. This pattern is linked to a continuation of enhanced low-level easterly trade winds and anomalous upper-level westerly winds over western and central equatorial pacific (MET 2010). Thus, with a huge catchment area, 
the freshwater inflows are persistently larger during the Northeast monsoon. The atmospheric conditions are relatively stable during the Southwest monsoon. This situation starts around June to September due to the weakened La Niña phenomenon. The Southwest monsoon is generally found to be drier than the intermonsoon periods, reflected by slower vertical mixing which reduces the strong convection process. Most of the areas in Peninsular Malaysia will have more days without rain (MET 2011). This resulted in the less freshwater inflow during the Southwest monsoon towards the Pahang River estuary.

\section{MATERIALS AND METHODS}

\section{Satellite Data and SPM Data}

Efficient and accurate retrieval of suspended particulate matter versus water surface reflectance relations for the study area requires two types of data: in-situ suspended particulate matter data and Landsat 7 ETM+ images. Eighteen scenes of Landsat 7 ETM images were acquired from Earth Resources Observation and Science (EROS) Center, United States Geological Survey (USGS). Scenes from path/row $126 / 57$ and 126/58 were selected because of the image data extent. It covered several Malaysian Department of Irrigation and Drainage (DID) suspended sediment gauge stations.

The images extent several DID suspended sediment gauge stations. Scene 126/57 covered suspended sediment gauge stations of Kampung Merting and Sungai Yap. Scene 126/58 covered Lubuk Paku, Temerloh and Sungai Teriang stations. Scene 127/57 covered Jeram Bungor, Sungai Perting and Kampung Batu Buaya stations.

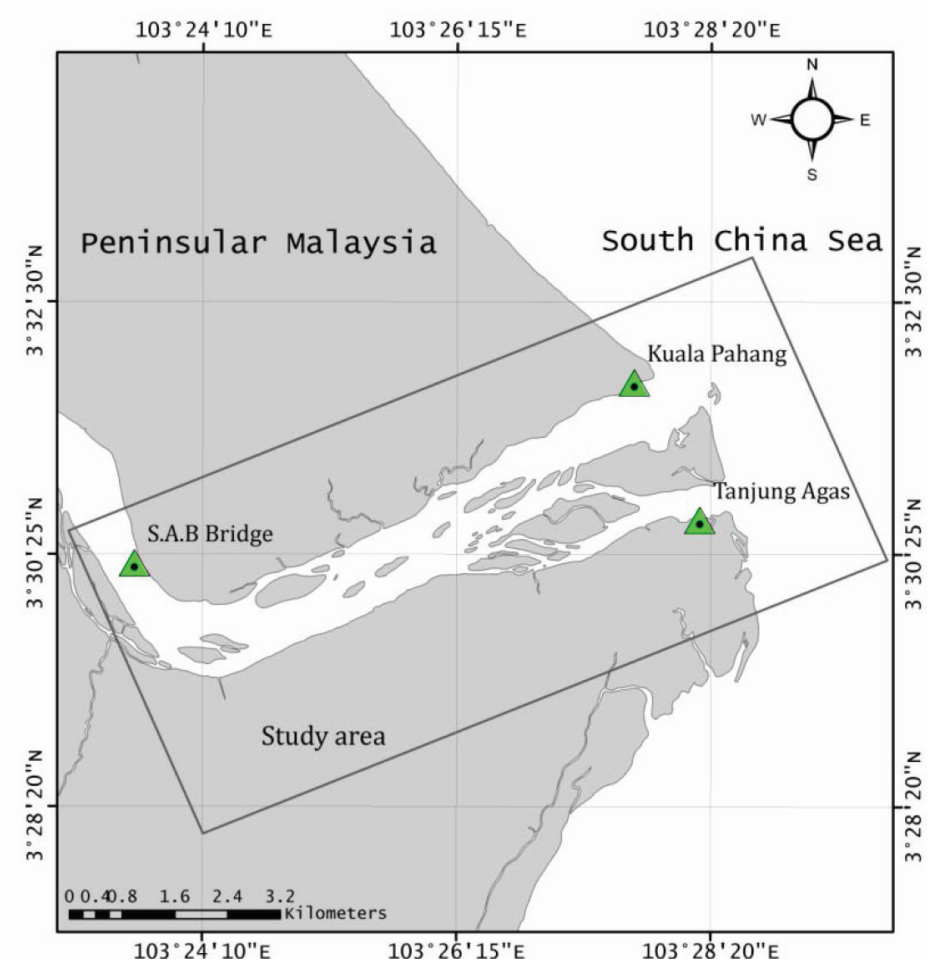

Figure 1. Study Area. 


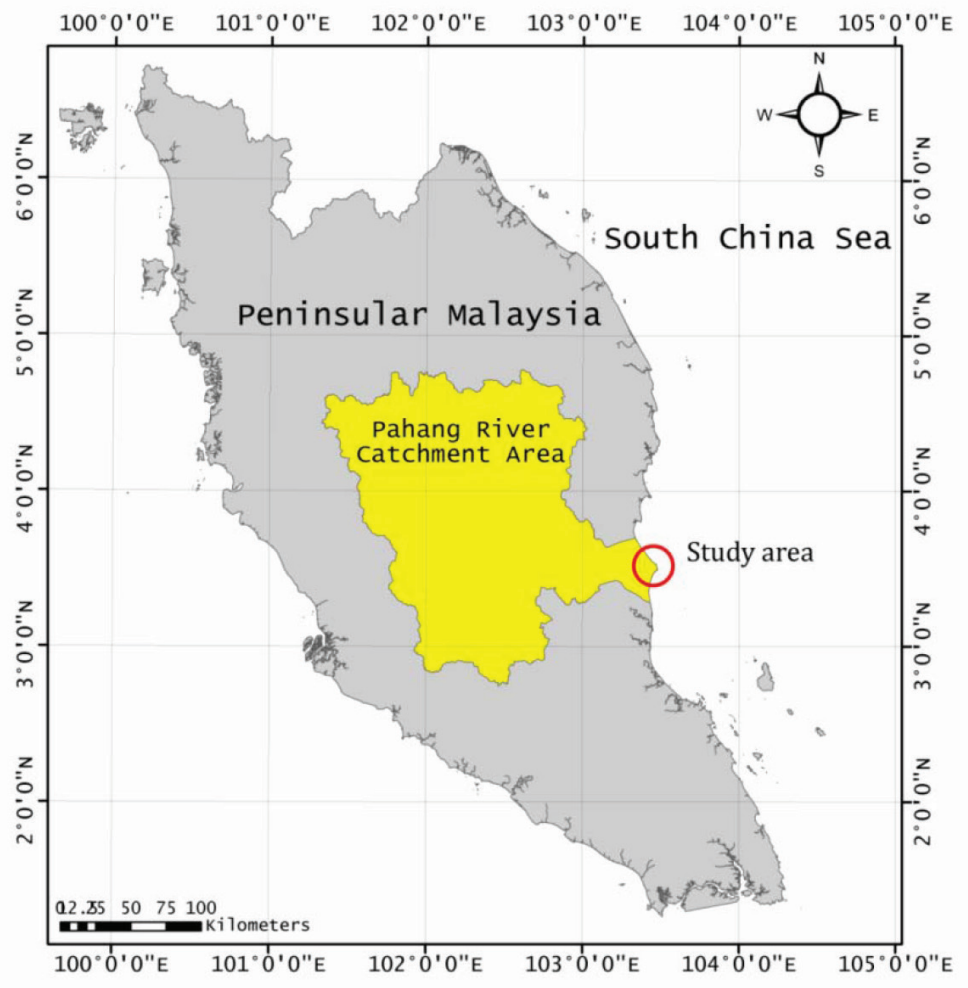

Figure 2. Boundary of the Pahang River catchment area.

The availability of both ETM+ images and suspended sediment data is a constraint for this study. It was difficult to obtain the satellite images and simultaneous suspended sediment data at the gauging stations. In certain image acquired date, only a few of the suspended data existed at DID gauging stations. Thus, archived suspended sediment data were obtained (as many as possible) from the gauging stations, which measured data on the same dates as these ETM+ images. In this study, 72 data information and images were compared between DID stations records and image reflectance/radiance. The gauging station recorded suspended sediment data in tonnes/day and flow, in $\mathrm{m}^{3} / \mathrm{s}$. These units need to be converted into $\mathrm{mg} / \mathrm{l}$ or $\mathrm{g} / \mathrm{l}$ for regression correlation with data from satellite images. Derived correlation equations were used to analyze SPM concentration from Landsat 7 ETM+ image of Pahang river estuary during the Northeast and Southwest monsoon period using ENVI 4.5 band maths expression.

\section{Calibration and Image Processing}

Each ETM+ image used was referenced to Rectified Skewed Orthomorphic (RSO) Malaysia projection. The Modified Everest and Kertau 1948 were applied to the projection spheroid and datum. The false Easting and Northing of the projection was 804671.29977 and 0 . The 1:50000 scale topographic map series L7070 edition 1-PPNM of Kuantan (Sheet 4360), Kuala Pahang (Sheet 4359) and Pekan (Sheet 4359) prepared by Department of Survey and Mapping Malaysia (JUPEM) were used. Image to map rectification were applied using 50 well distributed ground control points (GCPs) in the reference process. The root mean square error (RMSE) error was $\pm 0.22( \pm 5.5 \mathrm{~m}$ for $\mathrm{ETM}+$ data images). 
The satellite-generated digital numbers (DN) were converted to spectral radiance by removing the gain and offset effects introduced by the satellite system. The equation to convert DN to radiance $\left(\mathrm{Wm}^{2} \mathrm{sr}^{1} \mu \mathrm{m}^{1}\right)$ using gain and bias method (Equation 1) is as following:

$$
L \lambda=\text { Gain } \times D N+\text { Bias }
$$

where, $L \lambda$ is pixel value as radiance, $D N$ is digital number, Gain is gain value for specific band and Bias is bias value for specific band. The radiance pixels were converted to top of atmosphere reflectance using the following equation (Equation 2):

$$
\rho \lambda=\frac{\pi \times L \lambda \times d^{2}}{\operatorname{ESUN} \lambda \times \sin \theta}
$$

where, $\rho \lambda$ is unit less planetary reflectance, $L \lambda$ is radiance, $d$ is Earth-Sun distance in astronomical units, ESUN $\lambda$ is the mean solar exo-atmospheric irradiance and $\theta$ is sin sun elevation ( $\cos$ solar zenith $=\sin$ sun elevation $)$ (Chander et al. 2009).

Fast Line-of-sight Atmospheric Analysis of Spectral Hypercube (FLAASH) is MODTRAN4 based model which were used to analyze each image using multiple parameter input: scene acquisition information, sensor information, aerosol model and retrieval methods, cloud cover, reflectance factor data, and multispectral settings. It is to reduce the surface reflectance signals which constrain the reliability of the satellite image analysis due to scattering and absorption effects of water vapor and aerosols in the atmosphere (Matthew et al. 2000).

The images (path: 126 row: 58; dated $11 / 12 / 2010$ and $23 / 7 / 2011$ ) which had undergone geometric, radiometric and atmospheric corrections were subset for the extended study area. The output subset image were geo-referenced as the parent image. The subset procedures were carried out using AOI tools in ENVI 4.5. Mosaicking procedures were applied to the subset images to remove the clouds, cloud shadows and lands. The classifications were performed using Nearest Neighbour configuration and the output were exported in raster format for analysis.

\section{RESULTS}

Based on the power regression analysis, the relationship between SPM from DID station and images during the Northeast and Southwest monsoon is show in Figure 3 and Figure 4. The relationship results between similar parameters including the Inter-monsoon period is show in Figure 5.
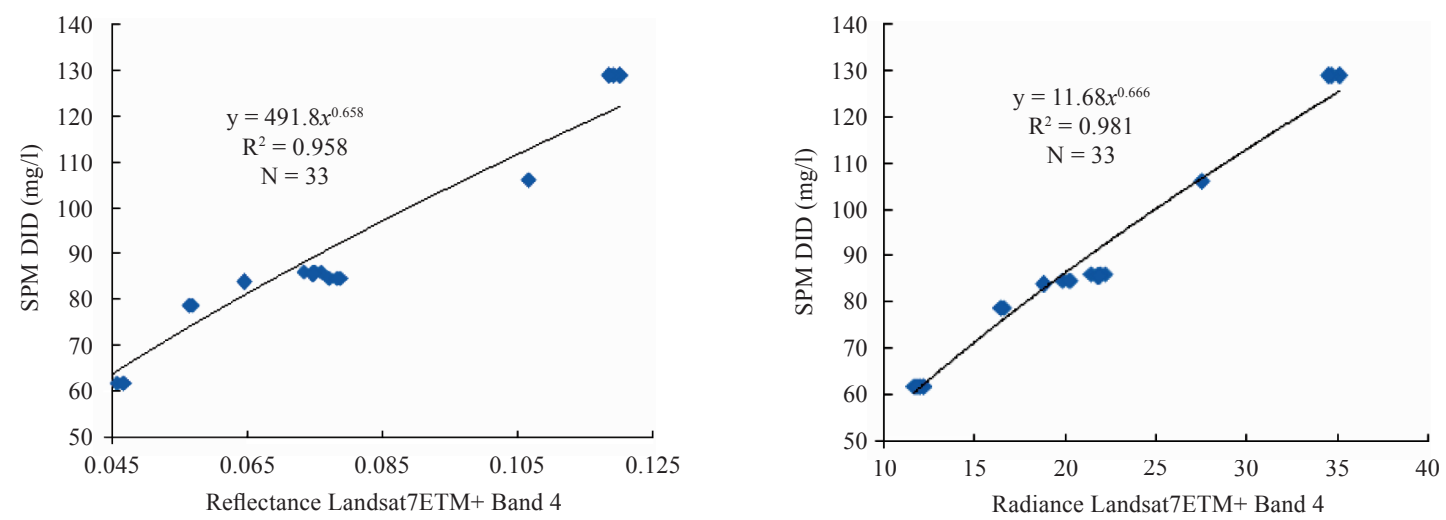

Figure 3. Regression analysis between SPM from ETM+ and SPM from DID station during the Northeast monsoon period (Left: SPM DID vs Reflectance; Right: SPM DID vs Radiance). 

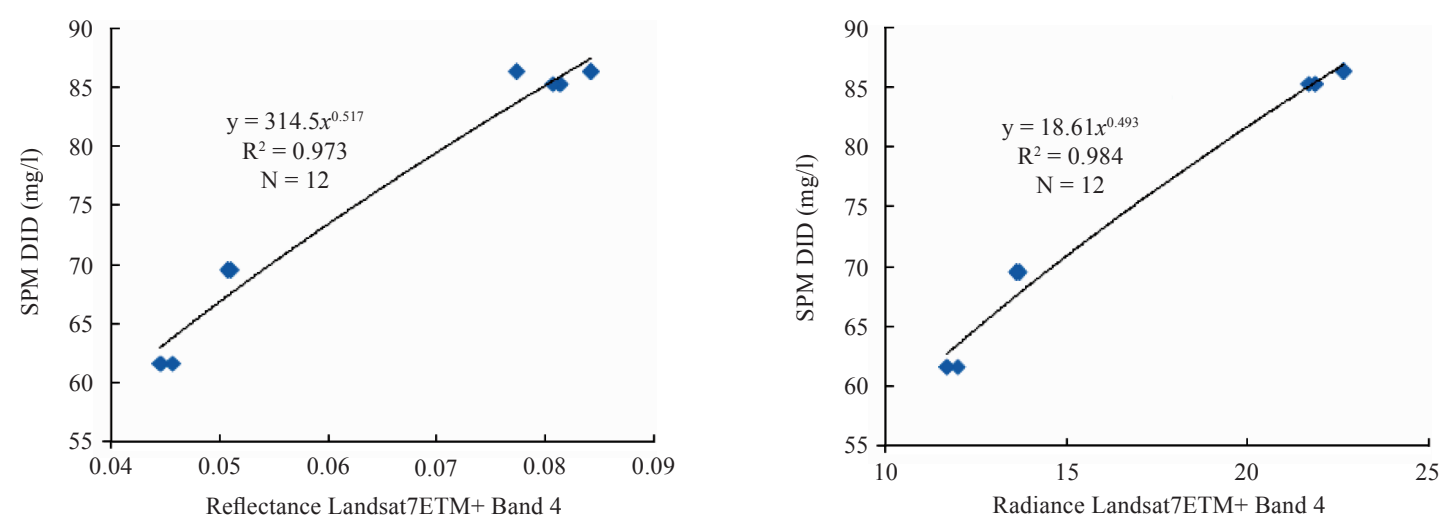

Figure 4. Regression analysis between SPM from ETM+ and SPM from DID station during the Southwest monsoon period (Left: SPM DID vs Reflectance; Right: SPM DID vs Radiance).
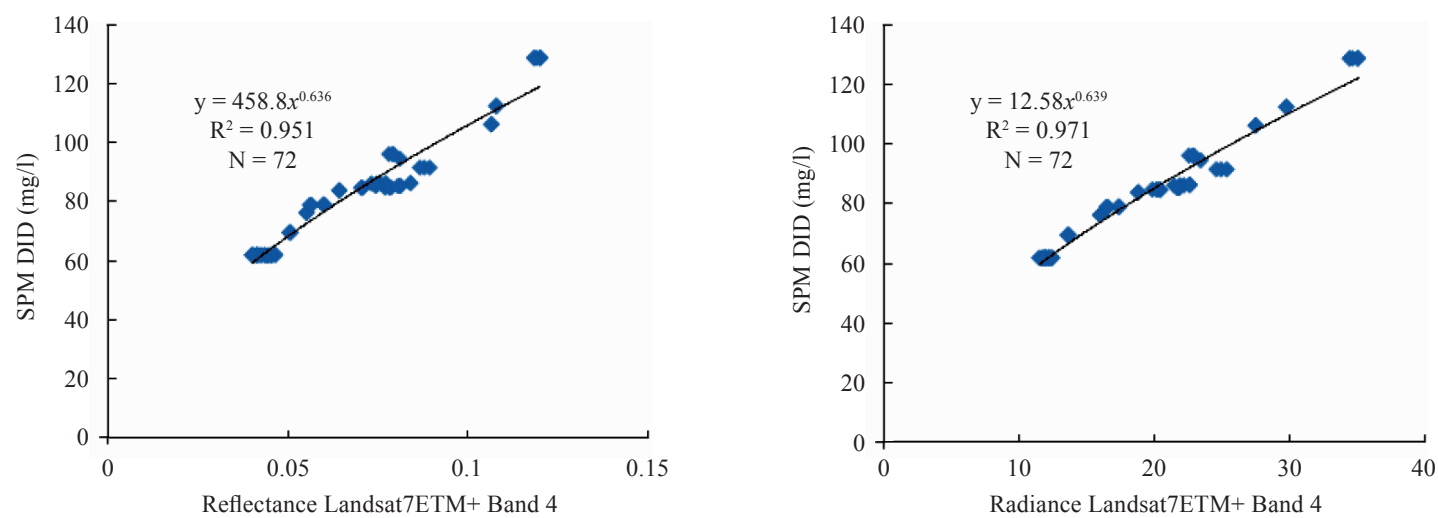

Figure 5: Regression analysis between total samples of SPM from ETM+ and SPM from DID station including intermonsoon (Left: SPM DID vs Reflectance; Right: SPM DID vs Radiance).

The relationship between images reflectance and radiance and SPM from DID was highly significant at $95 \%$ confidence level for both monsoons. Based on the higher significant $\mathrm{R}^{2}$ between the SPM from DID station and radiance, the relationship equations were thus selected. These new SPM equations had good predictive power for SPM retrieval in this study.

Based on the $F$-test, the $F$ calculated for all relationship were smaller than $F$ distributed. Therefore, the differences in variances between the datasets were statistically significant.
Using $t$-test assuming unequal variances, the values of $t$-calculated for all relationships were smaller than $t$-critical two tail and means are not statistically different. The $\mathrm{P}$ values were computed using $\mathrm{R}^{2}$ and degree of freedom (Df) with $\mathrm{p}<0.0001$ and considered to be extremely, statistically significant. In addition, the intercepts did not significantly differ from zero. The $\mathrm{R}^{2}$ values for relationship between SPM from DID station and radiance (L) was 0.981 for Northeast monsoon and 0.984 for Southwest monsoon. The standard errors for these equations were 0.878 for Northeast monsoon, and 0.717 for Southwest monsoon. 
Therefore, the following power was considered for power (Equation 3 and Equation 4):

$$
\begin{aligned}
& \operatorname{SPM} N E(\mathrm{mg} / \mathrm{l})=11.68 \mathrm{x}^{0.666} \\
& \operatorname{SPM~SW}(\mathrm{mg} / \mathrm{l})=18.61 \mathrm{x}^{0.493}
\end{aligned}
$$

where, $\mathrm{x}(\mathrm{TM} 4)$ is radiance $(L)$ of ETM NIR band 4 was developed under tropical atmospheric conditions and could be used for monitoring SPM concentration in tropical areas especially for the Pahang River. These equations were applied to the subset image of the Pahang River estuary and the following images are shown in Figure 6 and Figure 7.

In 2010, during the Northeast monsoon with specific date and time of 11/12/2010, 11:15:24 AM indicated the maximum SPM concentration of $145.63 \mathrm{mg} / 1$ and minimum SPM concentration value of $126.24 \mathrm{mg} / \mathrm{l}$. The mean SPM concentration value was 131.69 $\mathrm{mg} / \mathrm{l}$. Results from image analysis showed maximum reflectance value (factor between 0 to 1 ) of captured image as 0.157 . The minimum reflectance value was 0.126 and the mean reflectance value was 0.135 .
In 2011, during the Southwest monsoon with specific date and time of 23/07/2011, 11:15:54 AM indicated the maximum SPM concentration of $149.41 \mathrm{mg} / 1$ and minimum SPM concentration value of $81.45 \mathrm{mg} / \mathrm{l}$. The mean SPM concentration value was 95.94 $\mathrm{mg} / \mathrm{l}$. Results from image analysis showed maximum reflectance value (factor between 0 to 1 ) of captured image as 0.237 . The minimum reflectance value was 0.074 and the mean reflectance value was 0.078 .

Power regression was used for validations of derived equations; retrieved using SPM from image and SPM from proxies extracted from validated sediment transport models (Razak et al. 2013). The power regression analysis for Northeast monsoon in Figure 8 (left) show high significant at 95\% confidence level $(\mathrm{n}=100$, $\left.\mathrm{R}^{2}=0.907\right)$. The multiple $\mathrm{R}$ value was 0.952 and the adjusted $R^{2}$ value was 0.906 . The value of standard error was 0.755 with maximum standard error percentage was $1.25 \%$. Validation for Southwest monsoon in Figure 8 (right) show high significance at $95 \%$ confidence level

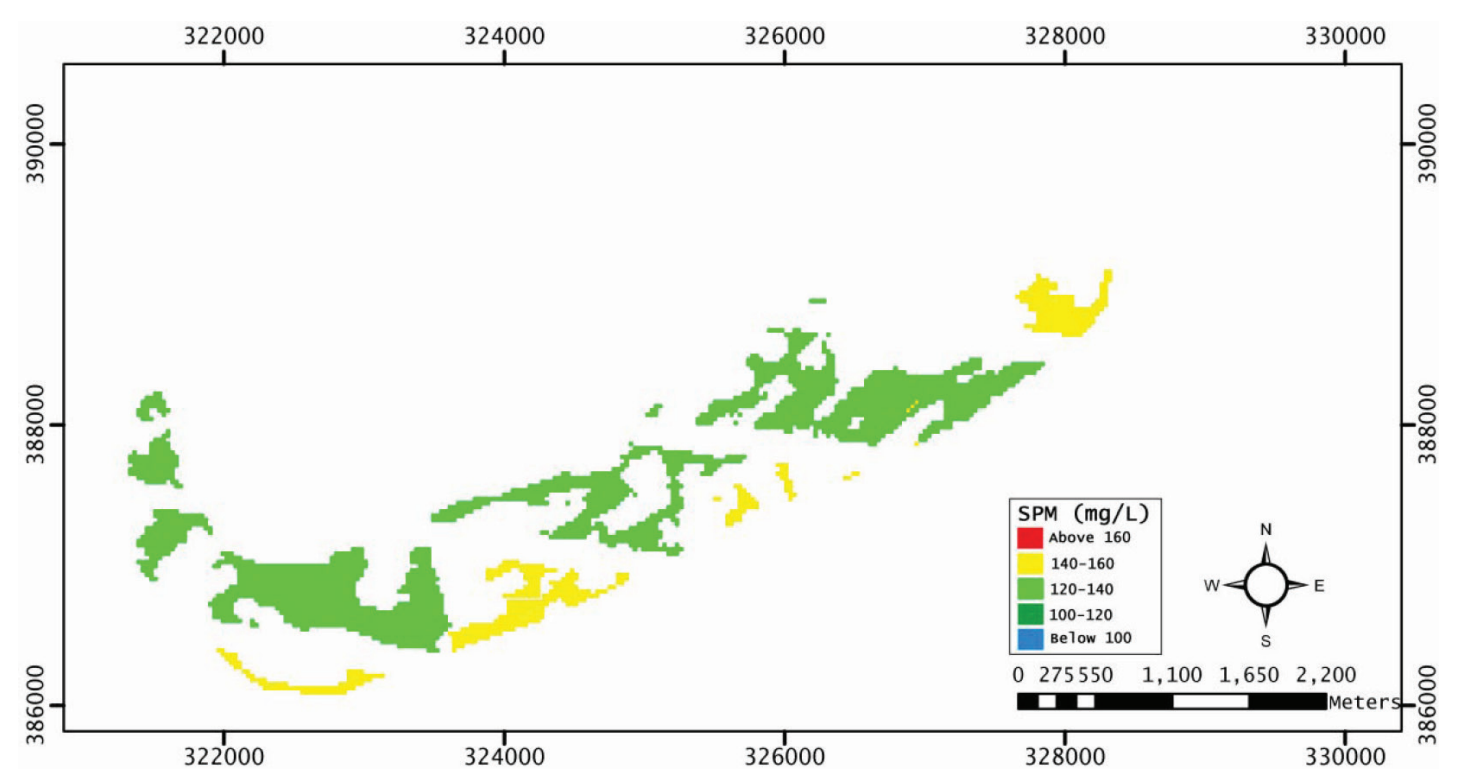

Figure 6. SPM concentration during Northeast Monsoon using Equation 3. 


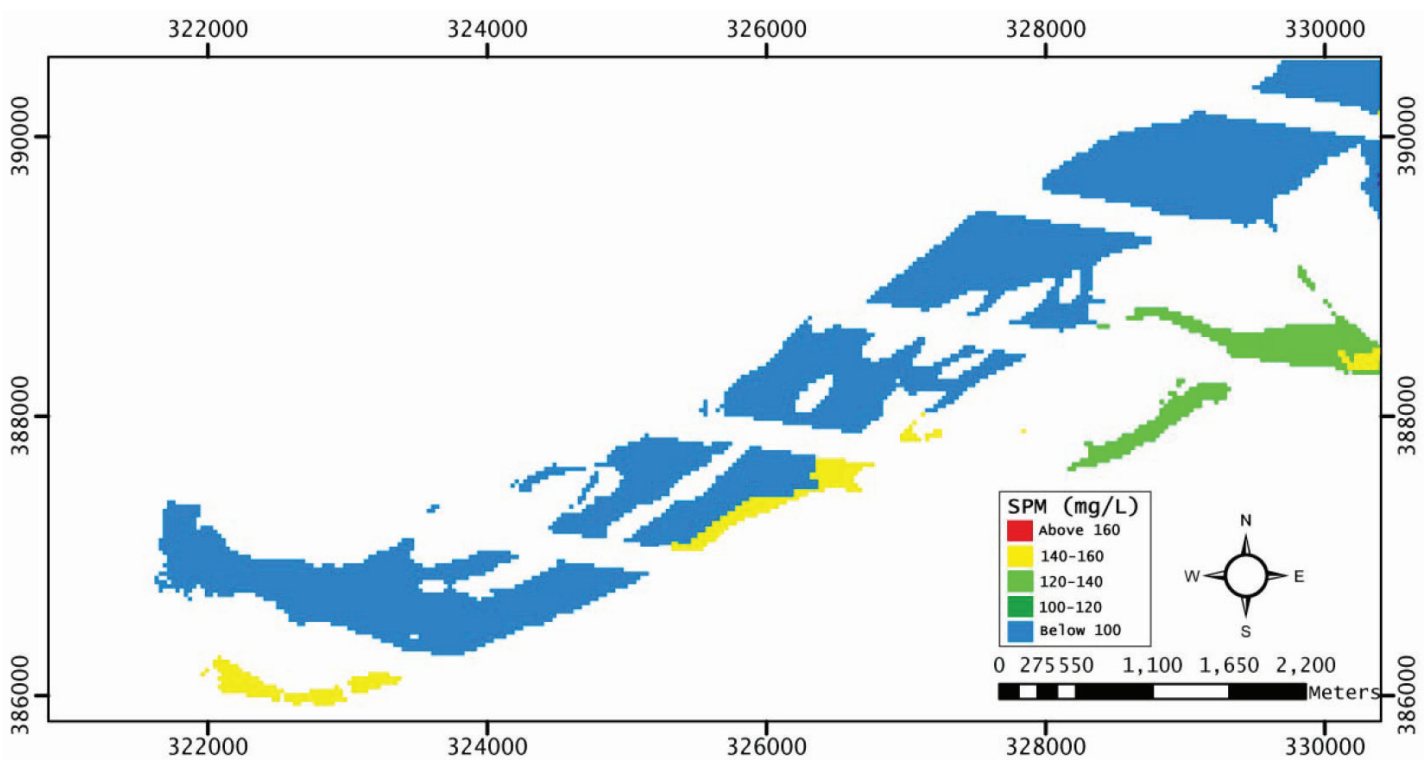

Figure 7. SPM concentration during Southwest monsoon using Equation 4.

( $\left.\mathrm{n}=100, \mathrm{R}^{2}=0.934\right)$. The multiple $\mathrm{R}$ value was 0.967 and the adjusted $R^{2}$ value was 0.934 . The value of standard error was 1.991 and the maximum standard error percentage was $2.37 \%$. Generally, from remote sensing archive data, the SPM concentrations of Pahang River were successfully determined from 1999 to 2012 as shown in Figure 9.

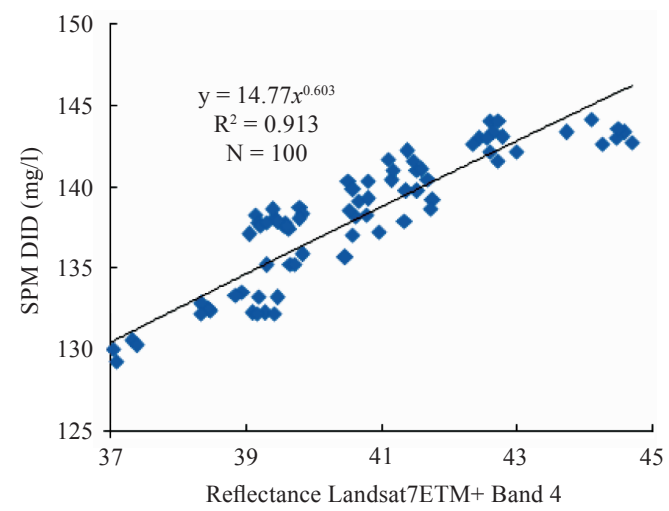

\section{DISCUSSIONS AND CONCLUSIONS}

The analyzed Landsat images provided SPM data for the surface water. High concentrations of suspended sediment were observed during Northeast monsoon from the analyzed images showing spatial distribution of SPM. The SPM concentration was higher than $>120$ $\mathrm{mg} / \mathrm{l}$, and in shallow channel of Tanjung

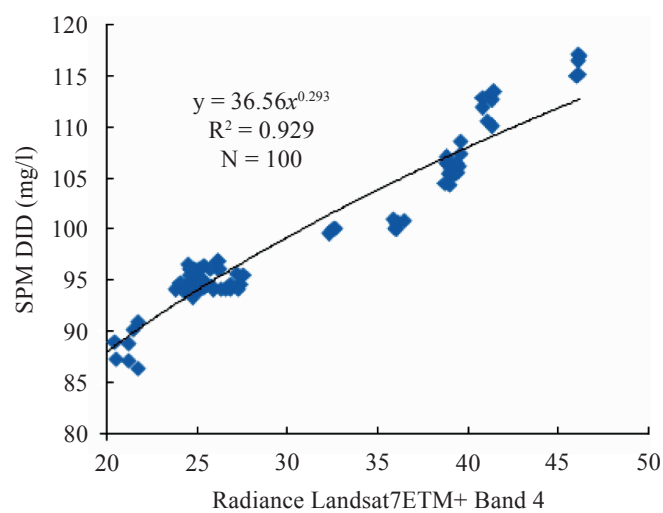

Figure 8. Validation using power regression analysis between SPM from ETM+ and SPM from proxies data of validated sediment transport model (Razak et al. 2013) during Northeast monsoon (left) and Southwest monsoon (right). 


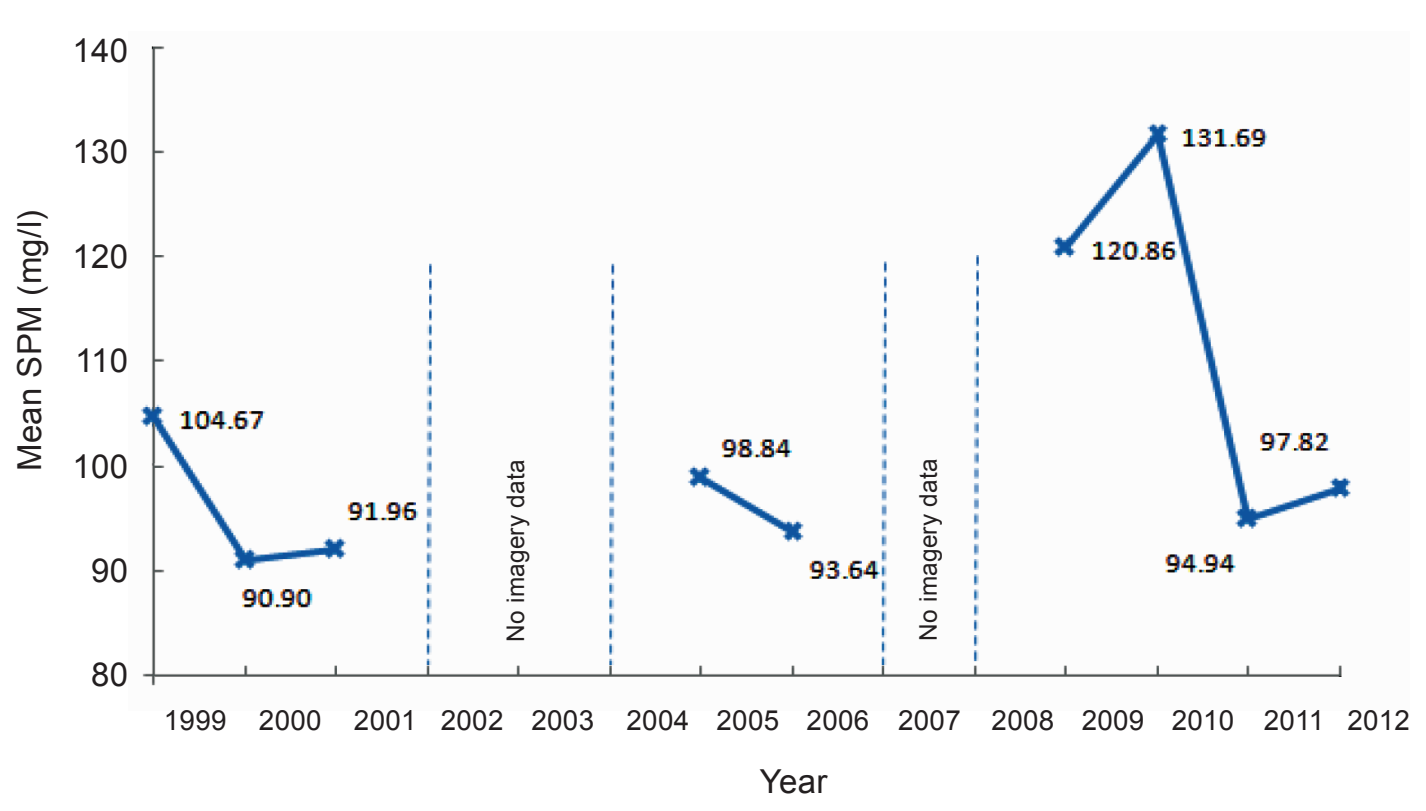

Figure 9. SPM concentrations of Pahang river estuary from archive images.

Agas, the concentration was between 140 $\mathrm{mg} / 1$ to $160 \mathrm{mg} / \mathrm{l}$. By contrast, relatively lower concentration in the deeper channel of Kuala Pahang was observed. The main transport pathway of the SPM is the deeper channel of Kuala Pahang, relating to the factors of channel size and discharge amount. It was observed that the smaller channel of Tanjung Agas retained more SPM, which induced sediment settlement. This condition also occured during Southwest monsoon with SPM in the deeper channel was less than $<100 \mathrm{mg} / \mathrm{l}$. The pattern of shallow channel retaining the SPM was similar, as the concentration in Tanjung Agas channel was between $140 \mathrm{mg} / 1$ to $160 \mathrm{mg} / 1$.

The reflectance representing SPM concentrations in Northeast monsoon were of higher value than Southwest monsoon, neglecting bottom reflectance. The factors associates with Northeast monsoon season were, high amount of discharge from upstream, also the turbulence of inflow and outflow water resulted from wave and discharge influences (Razak et al. 2013). Using remote sensing, the concentration of SPM could be retrieved from the satellite imagery. Yet, the exact condition of SPM concerning its transport could not be interpreted from spatially acquisition data as it only gave a one-time SPM concentration condition.

It was also found that equations that used SPM produced significant results compared to that of SSC. The satellite image mainly provided suspended sediment reflectance information as total bodies, not fractions of inorganic and organic materials. Generally, the equation correlation $\mathrm{R}^{2}$ depended on several factors: SSC limits, regional and specific additional reflectance data. Equations with high SSC limits were not suitable to be used in the Pahang river estuary based on the correlations. Some of the studies also focused on coastal areas that neglected the estuary properties such as freshwater discharges, thus it was inappropriate to represent Pahang river estuary. Morever, the significant reflectance data that used for each different study sites increased the responsive factors towards various changing on different regions. Although the study reliability might increase, it could not be adapted to other areas. 
Still, in studies related to suspended sediment concentration retrieval, both SSC and SPM values were needed as it described the sediment transport properties in the system.

Application of Equations 3 and 4 towards archive image of the Pahang river estuary showed decreasing pattern of SPM concentration in the earliest estimation year (1999) and slightly increased by year 2000 to 2001 . With no imagery data to support the whole pattern of view, the SPM concentration decreased from 2004 to 2006 . Yet, the pattern increased from year 2009 to 2010, and dropped in year 2011 . These data are significantly important in order to obtain historical view on the SPM distribution in the Pahang river estuary.

Although good correlations were produced, development of the equation for determining SPM as in Equations 3 and 4 required more extensive spatial data of SPM. Developed equation used image reflectance and radiance for comparisons with SPM. It is the fact that the atmospheric Rayleigh and aerosol scattering, which provide image additive effects, mainly influence the visible bands. Furthermore, near infrared and middle infrared wavelengths are affected by atmospheric absorption while the influence of air molecules and aerosol particle scattering are negligible in these ranges. It could be concluded that an application of atmospheric correction had a more significant effect on the maximum and minimum values than the effect on their average values.

\section{ACKNOWLEDGMENT}

This research has been funded by the International Islamic University Malaysia Research Grant (Ref: IIUM/202/C/1/1/AT107) and Fundamental Research Grant Scheme Vote 59247 from Ministry of Higher Education, Malaysia.

Date of submission: October2014

Date of acceptance: January 2015

\section{REFERENCES}

ATSM 2010, 'Standard test method for filterable matter (total dissolved solids) and non-filterable matter (total suspended solids) in water,' ATSM, DOI, pp. 10.1520/D5907-10.

Colleen, ML \& Tamlin, MP 2013, 'Remote sensing of suspended sediment concentration and hydrologic connectivity in a complex wetland environment', Remote Sens. Environ., vol. 129, pp. 197-209.

Dekker, AG, Vos, RJ \& Peters, SWM 2001, 'Comparison of remote sensing data, model results and in situ data for total suspended matter (TSM) in the southern Frisian Lakes', Sci. Total Environ., vol. 268, pp. 97-214.

Doxaran, D, Froidefond, JM \& Castaing, P 2003, 'Remote-sensing reflectance of turbid sedimentdominated waters, reduction of sediment type variations and changing illumination conditions effects by use of reflectance ratios', Applied Optics, vol. 42, pp. 2623-2634.

Giardino, C, Pepe, M, Brivio, P, Ghezzi, P \& Zilioni, E 2001, 'Detecting chlorophyll, Secchi disk depth and surface temperature in sub-alpine lake using Landsat imagery', Sci. Total Environ., vol. 268, pp. 19-29.

Gyanesh, C, Brian, LM \& Dennis, LH 2009, 'Summary of current radiometric calibration coefficients for Landsat MSS TM, ETM+, and EO-1 ALI sensors', Remote Sens. Environ., vol. 113, pp. 893-903.

Islam, MR, Yamaguchi, Y \& Ogawa, K 2001, 'Suspended sediment in the Ganges and Brahmaputra Rivers in Bangladesh, observation from TM and AVHRR data', Hydrol. Processes, vol. 15 , pp. 493-509.

Kabbara, N, Benkhelil, J, Awad, M \& Barale, V 2008, 'Monitoring water quality in the coastal area of Tripoli (Lebanon) using high-resolution satellite data', ISPRS. Photogramm Remote Sens., vol. 63, pp. 488-495.

Keiner, LE \& Yan, XH 1998, 'A neural network model for estimating Sea surface chlorophyll and sediments from thematic mapper imagery,' Remote Sens. Environ., vol. 66, pp. 153-165.

Kloiber, S, Brezonik, P \& Olmanson, L 2002, 'Bauer $\mathrm{M}$, 'A procedure for regional lake water quality assessment using Landsat multispectral data,' Remote Sens. Environ., vol. 82, pp. 38-47.

Matthew, MW, Adler-Golden, SM, Berk, A \& Richtsmeier, SC, Levine, RY, Bernstein, 
LS, Acharya, PK, Anderson, GP, Felde, GW, Hoke, MP, Ratkowski, A, Burke, HH, Kaiser, RD \& Miller, DP 2000, 'Status of Atmospheric Correction Using a MODTRAN4-based Algorithm', in SPIE Proceedings Algorithms for Multispectral, Hyperspectral, and Ultraspectral Imagery VI, vol. 4049, pp. 199-207.

MET 2010, 'Northeast monsoon report,' Malaysian Meteorological Department, Malaysia.

MET 2011, 'Southwest monsoon report,' Malaysian Meteorological Department, Malaysia.

Milan, O \& Pavla, P 2008, 'Retrieval of suspended particulate matter concentrations in the Danube River from Landsat ETM data', Sci. Total Environ., vol. 397, pp. 238-243.

Min, JE, Ryu, JH, Lee, S \& Son, SH 2012, 'Monitoring of suspended sediment variation using Landsat and MODIS in the Saemangeum coastal area of Korea', Marine Pollution Bulletin, vol. 64, pp. 382-390.

Pan, IL, Barzani, MG, khwan, MT, Sahibin, AR \& Khairul, AK 2001, 'Hydrological pattern of Pahang River basin and their relation to flood historical event', E-Bangi J., vol. 4, pp. 29-37.

Razak, Z, Zuhairi, A, Shahbudin, S \& Rosnan, Y 2013, 'Modelling suspended sediment transport in monsoon seasons: a case study of Pahang river estuary, Pahang, Malaysia', EGU General Assembly, vol. 15, pp. 2592.

Ritchie, JC \& Cooper, CM 1991, ‘An algorithm for estimating surface suspended sediment concentrations with Landsat MSS digital data', JAWRA, vol. 27, pp. 373-379.

Topliss, BJ, Almos, CL \& Hill, PR 1990, 'Algorithms for remote sensing of high concentration, inorganic suspended sediment', Int. J. Remote Sens., vol. 11, pp. 947-966. 